University of Nebraska - Lincoln

DigitalCommons@University of Nebraska - Lincoln

Evaluation of 6 ONRAB Ultralite bait flavor matrices delivered to coyotes (Canis latrans): Implications for oral rabies vaccination

\author{
Are R. Berentsen \\ USDA/APHIS/WS/National Wildlife Research Center \\ Stacey P. Brummer \\ USDA/APHIS/WS/National Wildlife Research Center \\ Julie K. Young \\ USDA/APHIS/WS/National Wildlife Research Center, julie.k.young@aphis.usda.gov \\ Kurt C. VerCauteren \\ USDA-APHIS-Wildlife Services, kurt.c.vercauteren@usda.gov
}

Follow this and additional works at: https://digitalcommons.unl.edu/icwdm_usdanwrc

Part of the Life Sciences Commons

Berentsen, Are R.; Brummer, Stacey P.; Young, Julie K.; and VerCauteren, Kurt C., "Evaluation of 6 ONRAB Ultralite bait flavor matrices delivered to coyotes (Canis latrans): Implications for oral rabies vaccination" (2014). USDA Wildlife Services - Staff Publications. 1446.

https://digitalcommons.unl.edu/icwdm_usdanwrc/1446

This Article is brought to you for free and open access by the U.S. Department of Agriculture: Animal and Plant Health Inspection Service at DigitalCommons@University of Nebraska - Lincoln. It has been accepted for inclusion in USDA Wildlife Services - Staff Publications by an authorized administrator of DigitalCommons@University of Nebraska - Lincoln. 
Research

\title{
Evaluation of 6 ONRAB Ultralite bait flavor matrices delivered to coyotes (Canis latrans): Implications for oral rabies vaccination
}

\author{
Are R. Berentsen ${ }^{\mathrm{a}, *}$, Stacey P. Brummer ${ }^{\mathrm{b}}$, Julie K. Young ${ }^{\mathrm{b}}$, Kurt C. VerCauteren ${ }^{\mathrm{a}}$ \\ ${ }^{a}$ USDA/APHIS/WS/National Wildlife Research Center, Fort Collins, Colorado \\ ${ }^{\mathrm{b}}$ USDA/APHIS/WS/National Wildlife Research Center, Predator Research Facility, Logan, Utah
}

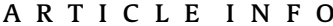

\section{Article history:}

Received 23 August 2013

Received in revised form

14 May 2014

Accepted 15 May 2014

Available online 28 May 2014

\section{Keywords:}

Canis latrans

coyote

ONRAB

oral rabies vaccination

rabies

\begin{abstract}
A B S T R A C T
The spread of rabies in terrestrial wildlife throughout the United States is primarily controlled through oral rabies vaccination. Relatively low bait acceptance and seroconversion rates by some target species have prompted investigation into an alternative to the RABORAL V-RG bait currently used. In Canada, ONRAB Ultralite baits are used to vaccinate raccoons (Procyon lotor) and striped skunks (Mephitis mephitis). Comparative studies between RABORAL V-RG and ONRAB found higher seroconversion rates among raccoons that ingested ONRAB, suggesting that it may be a suitable alternative. However, ONRAB has not been evaluated in many rabies reservoir species, including coyotes (Canis latrans). Vaccination of coyotes is a critical element in preventing reemergence of canine strain of rabies in the United States. We evaluated flavor preference of ONRAB Ultralite oral rabies vaccine baits by coyotes. Preferences among bait types differed (Friedman $\chi^{2}=13.28 ; d f=5 ; P=0.02$ ). Of the 6 bait flavors evaluated, cheese ranked the highest, followed by fish, chicken, sugar-vanilla, egg, and bacon flavors. Pairwise trials among the top 3 flavors (cheese, fish, and chicken) showed no difference (Friedman $\chi^{2}=3.00 ; d f=2 ; P=0.22$ ). Our research suggests that among the bait flavors we evaluated, cheese, fish, or chicken-flavored baits may be an appropriate flavor for delivery of ONRAB Ultralite baits to coyotes.
\end{abstract}

Published by Elsevier Inc.

\section{Introduction}

In the United States, more than $90 \%$ of reported rabies cases emerge from wildlife (Blanton et al., 2012). The raccoon (Procyon lotor) is largely regarded as the primary terrestrial wildlife reservoir, but other reservoirs including skunks (Mephitis mephitis), gray fox (Urocyon cinereoargenteus), and arctic fox (Vulpes lagopus) exist throughout the country (Slate et al., 2009). In 1994, an outbreak of canine rabies in coyotes (Canis latrans) and domestic dogs (Canis familiaris) in Texas prompted a statewide health emergency and rabies quarantine (Sidwa et al., 2005; Clark and Wilson, 1995). Coyotes can travel considerable distances (Kolbe and Squires, 2004; Carbyn and Paquet, 1985) and in 1991 contributed to the spread of canine rabies approximately $160 \mathrm{~km}$ north from the US-Mexico border (Clark and Wilson, 1995). In 1994, this strain of rabies spread to Florida via suspected human-mediated translocation of coyotes

\footnotetext{
* Address for reprint requests and correspondence: Are R. Berentsen, MS, USDA/ APHIS/WS/National Wildlife Research Center, 4101 LaPorte Avenue, Fort Collins, Colorado 80521, USA. Tel: +970-266-6221; Fax: +970-266-6157.

E-mail address: Are.R.Berentsen@aphis.usda.gov (A.R. Berentsen).
}

from Texas and caused a local rabies outbreak in domestic dogs (CDC, 1995). The United States was declared free from the canine strain of rabies in 2007, but the threat of reemergence of this strain remains (Velasco-Villa et al., 2008; Slate et al., 2009). Coyotes also may become infected with other strains of the virus, including the gray fox variant (Velasco-Villa et al., 2008), which is prevalent in regions of west-central Texas (DeYoung et al., 2009).

Spread of rabies in terrestrial wildlife is mitigated primarily through oral rabies vaccination (ORV) which is overseen by the National Rabies Management Program of USDA/APHIS/Wildlife Services (Slate et al., 2005). The only ORV bait currently licensed for use in wildlife in the United States is RABORAL V-RG (Merial, Inc, Atlanta, GA). However, desire for higher bait acceptance and seroconversion rates by reservoir species (primarily raccoons) that are currently being achieved with RABORAL V-RG has prompted investigation into alternative baits and vaccines. Seroconversion rates in raccoons range from $30 \%$ to $38 \%$ in some regions (FehlnerGardiner et al., 2012; Mainguy et al., 2013). In field trials, Linhart et al. (2002) found that bait visitation rates ranged from $14 \%$ to $38 \%$ depending on bait flavor, and of the baits visited, take rates ranged from $36 \%$ to $82 \%$. Furthermore, seroconversion rates were $44 \%$ and $94 \%$ in free-ranging coyotes that ingested fish meal- 
polymer baits and poultry-flavored baits, respectively (Linhart et al., 2002). Despite these differences, the same bait flavor (fish flavor) and vaccine combination is used to target multiple reservoir species (Slate et al., 2005). In Canada, vaccination of raccoons and striped skunks is performed using the ONRAB Ultralite bait (Artemis Technologies, Ontario, Canada; Rosatte et al., 2009). Field studies found 1.3-2.4 times higher seroconversion rates among raccoons that ingested ONRAB (51\%-74\%) versus RABORAL V-RG (30\%-38\%), suggesting that ONRAB may be a suitable alternative (FehlnerGardiner et al., 2012; Mainguy et al., 2013). However, ONRAB has not been evaluated in many terrestrial rabies reservoir species, including coyotes.

Much of the research into baits and attractants for coyotes has been associated with reducing livestock depredation (Turkowski et al., 1983; Guthery et al., 1984; Johnston 2005), eliciting specific behavioral responses (Kimball et al., 2000), or delivering biomarkers (Berentsen et al., 2006a). Additional research found differential responses of coyotes to various baits based on color (Mason et al., 1999) and relative neophobia (Harris and Knowlton, 2001; Windberg 1996). Results of these studies have provided a strong foundation on which to investigate baits for vaccine delivery. In order for an ORV bait to be effective, it must be attractive to the target species and elicit a chewing response which allows the vaccine to contact the buccal mucosa (Wandeler et al., 1988). To evaluate whether ONRAB may be a suitable vaccine for coyotes, it is necessary to determine whether the Ultralite baits that house the vaccine will be consumed and what flavor(s) of attractant may be preferred.

Investigations into ORV bait flavors and matrices for vaccinating coyotes have been performed with varying results. Frarry et al. (1998) found that although coyotes chewed dog food-flavored polymer baits 1.6 times more than fish-flavored baits, no flavor preference was exhibited, suggesting that either flavor may be suitable. In contrast, Fearneyhough et al. (1998) concluded that fish meal-flavored polymer baits were more effective in delivering ORV baits to coyotes than dog food-flavored polymer baits. Linhart et al. (2002) found that coyotes preferred sachet baits coated with fish meal, poultry, or cheese over sugar-flavored sachet baits. Our objective was to evaluate ONRAB Ultralite baits with various flavors incorporated into the bait matrix to determine which may be most suitable for use in distributing ONRAB Ultralite baits to coyotes.

\section{Materials and methods}

\section{Study site}

We conducted our study at the USDA/APHIS/Wildlife Services/ National Wildlife Research Center, Predator Research Station near Logan, Utah. Studies were conducted in $3.3 \mathrm{~m}^{2}$ kennels and in 0.1 ha outdoor pens. A more detailed description of the facility can be found in the study by Brummer et al. (2010).

\section{Bait}

The Ultralite bait, as used in the preparation of ONRAB vaccine baits, consists of an oval blister pack with an external waxy coating (Figure). All baits were the same size, shape, and color. The body of the blister pack measures $30 \times 14 \times 10 \mathrm{~mm}$ and has a rectangular lip extending to $40 \times 20 \mathrm{~mm}$ (Rosatte et al., 2009). Approximately $75 \%-80 \%$ of the external coating is composed of partially hydrogenated vegetable shortening, Microbond wax, stearine, and vegetable oil. The remaining $20 \%-25 \%$ is a flavor matrix composed of various commercially available food-derived products depending on the desired flavor. Six flavors were evaluated for flavor selection: bacon, cheese, chicken, egg, fish, and sugar-vanilla. Flavors chosen

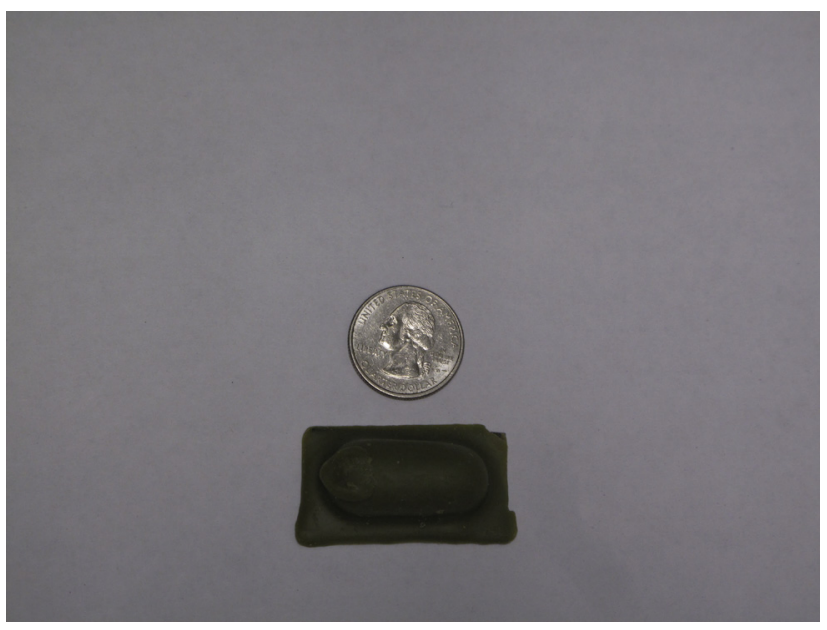

Figure. Ultralite oral rabies vaccination bait.

for evaluation were selected based on previous studies with coyotes (Fearneyhough et al., 1998; Frarry et al., 1998; Linhart et al., 2002) and other carnivores (Rosatte et al., 2009). Baits used in this study were placebos and contained water.

\section{Study design}

We conducted the study in 2 stages: (1) kennel trials and (2) outdoor enclosure trials. After the initial selection period, the top 3 selected baits were further evaluated in outdoor kennel trials. Coyotes selected for this study had not participated in previous studies involving baits, attractants, or lures for at least 18 months. Study subjects ranged in age from 2 to 8 years (average, 4.1 years). Study subjects were fed a daily ration of commercial mink food (Fur Breeders Agricultural Cooperative, Logan, UT) at the end of each trial day, and water was available ad libitum in accordance with the daily animal care schedule.

\section{Kennel trials}

We selected 10 coyotes ( 5 males and 5 females) from the colony to participate in the initial flavor evaluation stage in the kennels. The 6 bait flavors were paired so that each of 15 possible combinations was represented with each bait flavor introduced to each coyote 5 times. Bait pairs were randomly assigned without replacement to individual coyotes and offered before feeding at 2 pairs/d ( 3 pairs on the final study day) for 10 consecutive days. Coyotes were exposed to each bait pair for 15 minutes. We calculated the total number of times each bait flavor was consumed and selected the top 3 bait flavors for further evaluation. All coyotes were exposed to all bait combinations in a balanced randomized block design.

\section{Outdoor enclosure trials}

We selected 8 coyotes ( 4 males and 4 females) that had not participated in the kennel trials to participate in outdoor enclosure trials. Bait pairs were randomly assigned without replacement to individual coyotes and offered before feeding at 2 pairs/d. Each coyote was exposed to all 3 bait-pair combinations, resulting in each bait type offered twice in a balanced randomized block design. Coyotes were exposed to each bait pair for 30 minutes. This time was selected to allow researchers time to place all baits and leave the kennels and reduce the potential for distracting the study subjects. Bait placement location (left or right) and placement order 
(first or second) were randomly assigned. Baits were placed approximately $10 \mathrm{~m}$ apart to provide spatial independence. One person stood at the first bait to restrict coyote access to the bait, whereas the second was placed. Both persons left the enclosure simultaneously after placement. The enclosures at the Predator Research Center are equipped with portable den boxes located in the central observation building rather than traditional animal shifts. These den boxes are used to move animals in or out of an enclosure to provide veterinary care, and so forth. Because of the enclosure shape and size, numerous people are needed to herd individuals into the den box. This process is considered a stressful experience for the animal (personal communication with animal care staff). To reduce stress and its potential influence on study results, we randomized the order of bait placement rather than herding study subjects into den boxes to stage the baits.

\section{Data analysis}

We recorded all trials on digital video and evaluated footage daily. Overall bait consumption was divided into 2 categories: eaten (chewed and swallowed) and not eaten. Overall consumption was evaluated using Friedman analysis of variance (Hollander and Wolfe, 1973). Pairwise analysis was performed using the Wilcoxon signed-rank test (Ott and Longnecker, 2001). Data were analyzed using SPSS statistical software (SPSS Statistics for Windows, version 21.0; IBM Corp., Armonk, NY), with statistical significance given at $P<0.05$.

\section{Results}

\section{Kennel trials}

Each bait flavor was offered a total of 50 times: 5 times to each of 10 coyotes. Of 300 baits offered during the kennel trial, 25 (8\%) were picked up and dropped ( 4 of which were punctured). These baits were classified as "not eaten." A test for normality (Shapiro-Wilk test) showed significant left skew $(W=0.77 ; P<0.0001)$. Preferences among bait types differed (Friedman $\chi^{2}=13.28 ; d f=5 ; P=$ 0.02 ). Cheese-flavored baits ranked the highest (Table). In pairwise comparisons with cheese as the reference bait, preferences between fish and chicken did not differ. Differences between cheese and sugar-vanilla were borderline but not significant (Table).

\section{Outdoor trials}

Based on rankings during the kennel trials, we evaluated cheese, chicken, and fish-flavored baits during outdoor trials. Each bait flavor was offered total of 16 times: twice to each of 8 coyotes. A test for normality (Shapiro-Wilk test) shows significant left skew ( $W=$ $0.47 ; P<0.0001)$. Friedman test showed no statistical difference in preference in any of the 3 flavors $\left(\chi^{2}=3.00 ; d f=2 ; P=0.22\right)$.

Overall consumption data (left vs. right) for both kennel and outdoor trials were normally distributed (Shapiro-Wilk $W=0.96$;

\section{Table}

Bait flavor ranks and pairwise results

\begin{tabular}{llll}
\hline Bait flavor & Mean rank & \multicolumn{2}{l}{ Paired ranks test } \\
\cline { 3 - 4 } & & $Z$ & $P$ \\
\hline Cheese & 4.30 & $\mathrm{~N} / \mathrm{A}$ & $\mathrm{N} / \mathrm{A}$ \\
Fish & 4.10 & 0.000 & $>0.9$ \\
Chicken & 3.95 & -0.962 & 0.336 \\
Sugar-vanilla & 3.20 & -1.841 & 0.066 \\
Egg & 3.10 & -2.070 & 0.038 \\
Bacon & 2.35 & -2.232 & 0.026 \\
\hline
\end{tabular}

N/A, not applicable.
$P=0.61)$. There was no difference between consumption based on left or right placement $(F=1.52 ; d f=17 ; P=0.4)$.

\section{Discussion}

Our study provides information on bait flavor preferences in coyotes that may prove useful in using ONRAB to vaccinate coyotes against rabies. Interestingly, sugar-vanilla flavor, the primary flavor used for vaccinating raccoons and striped skunks in Canada (Rosatte et al., 2009), had among the lowest flavor selection rate among the baits tested. Although coyotes often ingest sweet tasting things (Marsh et al., 1982; Mason and McConnell, 1997; Berentsen et al., 2006b), our results suggest that this flavor may not be a suitable candidate for use in coyotes.

Flavor selection varied among coyotes. Six coyotes did not eat either bait during at least 1 trial, and 1 of the 6 did not consume any bait during 11 trials. It is possible that satiety played a role in lack of bait ingestion, but given the relatively small size of the baits, satiety is unlikely. Furthermore, if aversion was contributing a factor, we would expect to see bait consumption decrease over time with the lowest rate of bait consumption occurring during the third trial on the final day. Such a decrease was not seen; the events in question were distributed throughout the trials, and there was no change in bait consumption on the final day. Variation in bait consumption is likely because of the individuality of each study subject.

Our research suggests that among bait flavors we tested, cheese, chicken, or fish-flavored baits may be equally appropriate flavor for delivery of ONRAB Ultralite baits to coyotes.

Rosatte et al. (1998) found that cheese-flavored and sugarvanilla-flavored baits were equally preferred by raccoons, but manufacturing sugar-vanilla-flavored baits proved more practical. Given our results, cheese flavor could conceivably be an effective attractant for both coyotes and raccoons. Gray foxes are another important rabies reservoir, and their range overlaps that of coyotes (Whittaker and Hamilton, 1998). Steelman et al. (2000) suggested that sugar-vanilla-flavored wax cake baits may be suitable for ORV delivery to gray foxes in Texas. Preliminary research suggests that gray foxes will ingest cheese-flavored ONRAB Ultralite baits (S. Johnson, 2013, unpublished data), but additional studies on uptake rates, flavor preference, and effectiveness of these baits in gray foxes are needed. Field research is currently being conducted in Texas and South Carolina to evaluate uptake of various ONRAB Ultralite bait flavors by free-ranging rabies reservoir species, including gray foxes, coyotes, and raccoons. This research may reveal whether it is feasible to use a single flavor as a multispecies ORV bait.

With the elimination of the canine strain of rabies from the United States (Velasco-Villa et al., 2008; Slate et al., 2009), one may question the utility of a coyote-specific ORV bait. Although such a question is appropriate, the threat of reemergence of the canine strain remains along the US border with Mexico, where domestic dogs and coyotes were responsible for the rabies outbreak in the late 1980s and 1990s. From a rabies management standpoint, a coyote-specific ORV bait may still be warranted in localized bait distribution along the southern border of the United States.

Caution must be exercised when extrapolating studies with captive animals to their free-ranging counterparts. Wild coyotes are likely in a somewhat constant state of hunger. Thus, it is likely that bait may be consumed when encountered no matter the flavor, provided the bait is perceived as a food item. Other challenges surrounding "cafeteria" style presentation is the question of "call distance." That is, how far can an animal detect different bait flavors? It may be the case that one bait draws the animal in, whereas another is selected. This is an area in need of further research. 


\section{Acknowledgments}

Funding was provided by the National Rabies Management Program. This research was approved by the USDA National Wildlife Research Center Institutional Animal Care and Use Committee under protocol QA-1955. The authors thank to H. Rowland for statistical assistance.

\section{Conflict of interest}

The authors declare no conflict of interest.

\section{References}

Berentsen, A.R., Johnston, J.J., Mauldin, R.E., Schmidt, R.H., 2006a. Using the CLOD to deliver pentachlorobenzene to coyotes (Canis latrans). Proc. Vert. Pest. Conf. 22, $277-281$.

Berentsen, A.R., Schmidt, R.H., Timm, R.M., 2006b. Repeated exposure of coyotes to the Coyote Lure Operative Device. Wildl. Soc. Bull. 34, 809-814.

Blanton, J.D., Dyer, J., McBrayer, J., Rupprecht, C.E., 2012. Rabies surveillance in the United States during 2011. J. Am. Vet. Med. Assoc. 241, 712-722.

Brummer, S.P., Gese, E.M., Shivik, J.A., 2010. The effect of enclosure type on the behavior and heart rate of captive coyotes. Appl. Anim. Behav. Sci. 125, 171-180.

Carbyn, L.N., Paquet, P.C., 1985. Long distance movement of a coyote from Riding Mountain National Park. J. Wildl. Manage. 50, 89.

Centers for Disease Control and Prevention [CDC], 1995. Translocation of coyote rabies-Florida, 1994. Morb. Mortal. Wkly. Rept. 44, 580-581, 587.

Clark, K.A., Wilson, P.J., 1995. The coyote's role in a rabies epizootic. In: Rollins, D., Richardson, C., Blankenship, T., Canon, K., Henke, S. (Eds.), Coyotes in the Southwest: A Compendium of Our Knowledge. Texas Parks and Wildlife Department, Austin, pp. 41-45.

DeYoung, R.W., Zamorano, A., Mesenbrink, B.T., Campbell, T.A., Leland, B.R., Moore, G.M., Honeycutt, R.L., Root, J.J., 2009. Landscape-genetic analysis of population structure in the Texas gray fox oral rabies vaccination zone. J. Wildl. Manage. 73, 1292-1299.

Fearneyhough, M.G., Wilson, P.J., Clark, K.A., Smith, D.R., Johnston, D.H., Hicks, B.N., Moore, G.M., 1998. Results of an oral rabies vaccination program for coyotes. J. Am. Vet. Med. Assoc. 212, 498-502.

Fehlner-Gardiner, C., Rudd, R., Donovan, D., Slate, D., Kempf, L., Badcock, J., 2012. Comparing ONRAB ${ }^{\circledR}$ and RABORAL V-RG ${ }^{\circledR}$ oral rabies vaccine field performance in raccoons and striped skunks, New Brunswick, Canada, and Maine, USA. J. Wildl. Dis. 48, 157-167.

Frarry, S.C., Henke, S.E., Anderson, A.M., Fearneyhough, M.G., 1998. Responses of captive and free-ranging coyotes to oral rabies vaccine baits. J. Wildl. Dis. 34, 13-22.

Guthery, F.S., Meinzer, W.P., Beasom, S.L., Caroline, M., 1984. Evaluation of placed baits for reducing coyote damage in Texas. J. Wildl. Manage. 48, 621-626.

Harris, C.E., Knowlton, F.F., 2001. Differential responses of coyotes to novel stimuli in familiar and unfamiliar settings. Can. J. Zool. 79, 2005-2013.

Hollander, M., Wolfe, D.A., 1973. Nonparametric Statistical Methods. John Wiley \& Sons, New York, USA.

Johnston, J.J., 2005. Evaluation of cocoa- and coffee-derived methylxanthines as toxicants for the control of pest coyotes. J. Agr. Food Chem. 53, 4069-4075.
Kimball, B.A., Mason, J.R., Blom, F.S., Johnston, J.J., Zemlicka, D.E., 2000. Development and testing of seven new synthetic coyote attractants. J. Agr. Food Chem. 48, $1892-1897$.

Kolbe, J.A., Squires, J.R., 2004. Long distance movement by a coyote within the Rocky Mountains. Northwest Sci. 78, 344-345.

Linhart, S.B., Wlodkowski, J.C., Kavanaugh, D.M., Motes-Kreimeyer, L., Montoney, A.J., Chipman, R.B., Slate, D., Bigler, L.L., Fearneyhough, M.G., 2002. A new flavor-coated sachet bait for delivering oral rabies vaccine to raccoons and coyotes. J. Wildl. Dis. 3, 363-377.

Mainguy, J., Fehlner-Gardiner, C., Slate, D., Rudd, R.J., 2013. Oral rabies vaccination in raccoons: comparison of ONRAB ${ }^{\circledR}$ and RABORAL V-RG ${ }^{\circledR}$ vaccine-bait field performance in Québec, Canada and Vermont, USA. J. Wildl. Dis. 49, 190-193.

Marsh, R.E., Howard, W.E., McKenna, S.M., Butler, B., Barnum, D.A., Teranishi, R., 1982. A new system for delivery of predacides or other active ingredients for coyote management. Proc. Vert. Pest Conf. 10, 229-233.

Mason, J.R., Belant, J., Barras, A.E., Guthrie, J.W., 1999. Effectiveness as color as an M-44 attractant for coyotes. Wildl. Soc. Bull. 27, 86-90.

Mason, J.R., McConnell, J.E., 1997. Hedonic responses of coyotes to 15 aqueous taste solutions. J. Wildl. Res. 2, 21-24.

Ott, R.L., Longnecker, M., 2001. An Introduction to Statistical Methods and Data Analysis, 5th edition. Duxbury Thomson Learning, Pacific Grove, CA, USA.

Rosatte, R.C., Donovan, D., Davies, J.C., Allan, M., Bachmann, P., Stevenson, B., Sobey, K., Brown, L., Silver, A., Bennett, K., Buchanan, T., Brucs, L., Givson, M. Beresford, A., Beath, A., Fehlner-Gardiner, C., Lawson, K., 2009. Aerial distribution of ONRAB baits as a tactic to control rabies in raccoons and striped skunks in Ontario, Canada. J. Wildl. Dis. 45, 363-374.

Rosatte, R.C., Lawson, K.F., MacInnes, C.D., 1998. Development of baits to deliver oral rabies vaccine to raccoons in Ontario. J. Wildl. Dis. 34, 647-652.

Sidwa, T.J., Wilson, P.J., Moore, G.M., Oertli, E.H., Hicks, B.N., Rohde, R.E. Johnston, D.H., 2005. Evaluation of oral rabies vaccination programs for control of rabies epizootics in coyotes and gray foxes: 1995-2003. J. Am. Vet. Med. Soc. 5, 785-792.

Slate, D., Algeo, T.P., Nelson, K.M., Chipman, R.B., Donovan, D., Blanton, J.D., Niezgoda, M., Rupprecht, C.E., 2009. Oral rabies vaccination in North America: opportunities, complexities, and challenges. PLoS Neglect. Trop. Des. 3 (12) e549. http://dx.doi.org/10.1371/journal.pntd.0000549.

Slate, D., Rupprecht, C.E., Rooney, J.A., Donovan, D., Lein, D.H., Chipman, R.B., 2005 Status of oral rabies vaccination in wild carnivores in the United States. Virus Res. 111, 68-76.

Steelman, H.G., Henke, S.E., Moore, G.M., 2000. Bait delivery for oral rabies vaccine to gray foxes. J. Wildl. Dis. 36, 744-751.

Turkowski, F.J., Popelka, M.L., Bullard, R.W., 1983. Efficacy of odor lures and baits for coyotes. Wildl. Soc. Bull. 11, 136-145.

Velasco-Villa, A., Reeder, S.A., Orciari, L.A., Yager, P.A., Franka, R., Blanton, J.D., Zuckero, L., Hunt, P., Oertli, E.H., Robinson, L.E., Rupprecht, C.E., 2008. Enzootic rabies elimination from dogs and reemergence in wild terrestrial carnivores, United States. Emerg. Infect. Dis. 14, 1849-1854.

Wandeler, A.I., Capt, S., Kappeler, A., Hauser, R., 1988. Oral immunization of wildlife against rabies: concept and first field experiments. Clin. Infect. Dis. 10 s649-s653.

Whitaker, J.O., Hamilton, W.J., 1998. Mammals of the Eastern United States. Comstock Books, Ithaca, New York, USA.

Windberg, L.A., 1996. Coyote responses to visual and olfactory stimuli related to familiarity with an area. Can. J. Zool. 74, 2248-2253. 